\title{
Breast cancer patients' clinical outcome measures are associated with Src kinase family member expression
}

\author{
B Elsberger', R Fullerton', S Zino', F Jordan², TJ Mitchell', VG Brunton ${ }^{3}$, EA Mallon ${ }^{4}$, PG Shiels' \\ and J Edwards*,I
}

'Western Infirmary Glasgow, Section of Surgery, Division of Cancer Sciences and Molecular Pathology, Faculty of Medicine, Level 2, McGregor Building, Dumbarton Road, Glasgow GII 6NT, UK; ${ }^{2}$ Western Infirmary Glasgow, Division of Developmental Medicine Reproductive and Maternal Medicine, Faculty of Medicine, Level 3, McGregor Building, Dumbarton Road, Glasgow GI I 6NT, UK: ${ }^{3}$ Edinburgh Cancer Research Centre, University of Edinburgh, Crewe Road, Edinburgh EH4 2XR, UK; ${ }^{4}$ Western Infirmary Glasgow, Department of Pathology, Dumbarton Road, Glasgow GII 6NT, UK

\begin{abstract}
BACKGROUND: This study determined mRNA expression levels for Src kinase family (SFK) members in breast tissue specimens and assessed protein expression levels of prominent SFK members in invasive breast cancer to establish associations with clinical outcome. Ki67 was investigated to determine association between SFK members and proliferation.

METHODS: The mRNA expression levels were assessed for eight SFK members by quantitative real-time PCR. Immunohistochemistry was performed for c-Src, Lyn, Lck and Ki67.

RESULTS: mRNA expression was quantified in all tissue samples. SRC and LYN were the most highly expressed in malignant tissue. LCK was more highly expressed in oestrogen receptor (ER)-negative, compared with ER-positive tumours. High cytoplasmic Src kinase protein expression was significantly associated with decreased disease-specific survival. Lyn was not associated with survival at any cellular location. High membrane Lck expression was significantly associated with improved survival. Ki67 expression correlated with tumour grade and nuclear c-Src, but was not associated with survival.

CONCLUSIONS: All eight SFK members were expressed in different breast tissues. Src kinase was highest expressed in breast cancer and had a negative impact on disease-specific survival. Membrane expression of Lck was associated with improved clinical outcome. High expression of Src kinase correlated with high proliferation.

British Journal of Cancer (2010) 103, 899-909. doi: I0.1038/sj.bjc.6605829 www.bjcancer.com

Published online 17 August 2010

(c) 2010 Cancer Research UK
\end{abstract}

Keywords: Src kinase family members; breast cancer; quantitative real-time PCR; immunohistochemistry; disease-specific survival

In 1911 Peyton Rous discovered v-Src, an avian retrovirus, causing transmissible sarcoma in chicken. This was followed by the discovery of c-Src, the human cellular counterpart of v-Src (Stehelin et al, 1976). It has now been established, that c-Src is part of a family of non-receptor tyrosine kinases containing eight family members expressed in mammalian cells that are involved with cancer progression and invasion (Brown and Cooper, 1996; Manning et al, 2002). c-Src, Fyn and Yes are widely expressed, whereas Lck, Hck, Fgr, Blk and Lyn are more selectively expressed in specific tissues (Irby and Yeatman, 2000; Palacios and Weiss, 2004). All Src family kinase (SFK) members have a similar structure: a C-terminal tail, four conserved Src homology domains and a unique amino-terminal domain that varies between the family members (Martin, 2001; Engen et al, 2008).

Src kinase has been investigated for a long time in a variety of solid tumours. Data from human cancer tissues have further defined the role of Src in tumour development in a more clinically relevant setting. Elevated levels of Src or SFKs have been detected in a range of human solid tumours, including glioblastoma (Kleber

*Correspondence: Dr J Edwards; E-mail: jel0b@clinmed.gla.ac.uk Received 6 May 2010; revised 30 June 2010; accepted 4 July 2010; published online 17 August 2010 et al, 2008), cancers of the prostate (Tatarov et al, 2009), breast (Verbeek et al, 1996), pancreas (Fu et al, 2006), colon (Bolen et al, 1987) and lung (Masaki et al, 2003). In vitro evidence for a role for c-Src in breast cancer is convincing, but currently hardly supported by translational clinical studies. In breast cancer, Src activity and distribution might impact on resistance to endocrine therapy in patients with oestrogen receptor/progesterone receptor (ER/PgR)-positive disease. Elevated c-Src activity promotes cellular invasion and motility in tamoxifen-resistant breast cancer cells (Hiscox et al, 2006) and provides a link between the HER family and steroid receptors (Yeatman, 2004; Likhite et al, 2006). Campbell et al (2008) illustrated that activated Src localised to the nucleus was significantly associated with improved overall survival and a lower recurrence rate during tamoxifen treatment of ER/PgR-positive tumours.

Other Src family members have also been linked with breast cancer. Again, there is little published evidence on the role of other Src family members in clinical breast cancer specimen. It is well established that Lyn has an important role in leukaemia. This has been suggested by several studies (Roginskaya et al, 1999; Wilson et al, 2002; Warmuth et al, 2003). Lyn is also involved in the development of certain solid tumours. Colon carcinoma cells use Lyn in the activation of the Akt (anti-apoptotic) pathway, and chemoresistant colonic cancer cells displayed elevated Lyn kinase 
activity (Bates et al, 2001). Inhibition of Lyn in prostate cancer cell lines resulted in reduced proliferation in vitro and in prostatic cancer xenograft models (Goldenberg-Furmanov et al, 2004). A recently published study shows that Lyn was associated with shorter overall survival, and that RNAi knockdown of Lyn in breast cancer cell lines inhibited cell migration and invasion, but not proliferation (Choi et al, 2010). Microarray studies have demonstrated that Lyn is induced in models of endocrine resistance (Gee et al, 2006) and Lck is implicated in hypoxiainduced breast cancer progression (Chakraborty et al, 2006).

The aim of the present study was therefore to establish mRNA expression levels for SFK members in human breast tissue and, subsequently, to assess protein expression of the most abundantly expressed SFK members, in a larger cohort of invasive breast cancer patients, to determine whether these are linked to clinical outcome measures.

\section{MATERIALS AND METHODS}

\section{Patients}

The study was granted approval by the local ethics committee for both the cohort used to determine mRNA expression (reverse transcriptase PCR (RT-PCR) cohort) and the cohort used to determine protein expression (immunohistochemistry (IHC) cohort).

The RT - PCR cohort contained 139 patients and was subdivided into Patient group $1(\mathrm{M})$, consisting of malignant tissue samples taken from 81 breast cancer patients at the time of primary tumour resection. All patients were diagnosed with invasive breast carcinoma between 1987 and 2005 in the Greater Glasgow area. Patient group 2 (NM) included non-malignant tissue samples from 48 breast cancer patients taken from disease-free areas of mastectomy resection specimens. Patient group $3(\mathrm{~N})$ comprised of 10 normal breast tissue specimens obtained from reduction mammoplasties. The ER status was determined in a routine diagnostic laboratory.

The IHC cohort is completely distinct from the PCR cohort with no overlapping patients. All patients in the IHC cohort were diagnosed with primary operable breast cancer between 1980 and 1999 and received standard adjuvant treatment according to protocols at the time of diagnosis. Only patients with full clinical data available were included in analysis. All tissue samples were taken at the time of surgical resection, assessed and determined by a pathologist.

\section{Quantitative reverse transcriptase PCR}

Tissue processing After resection of the primary tumour, representative parts of malignant and non-malignant breast tissue were identified by a pathologist, snap frozen and stored in liquid nitrogen. Normal breast tissue was selected and taken from different sites of breast reduction specimens.

RNA isolation Total mRNA was extracted from 50 to $75 \mathrm{mg}$ of breast tissue using the TRIZOL (Invitrogen, Paisley, UK) method according to manufacturer's protocol. RNA quantity and quality was assessed by UV spectrometry (GeneQuant machine, GE Healthcare, Little Chalfont, UK) and by examination of rRNA bands after agarose gel electrophoresis. Only samples that showed both $18 \mathrm{~S}$ band and a stronger expressed $28 \mathrm{~S}$ band were used.

cDNA synthesis A measure of $1000 \mathrm{ng}$ of RNA was treated with RNAse-free DNAse and removal reagent kit (Applera, Warrington, $\mathrm{UK})$, and random hexamer primers $(50 \mathrm{ng}$ ) were used for First Strand cDNA synthesis using SuperScript II RT (Invitrogen). Before using cDNA for PCR amplification, $2 \mathrm{U}$ of RNase $\mathrm{H}$ (Applera) were added to samples and incubated for $20 \mathrm{~min}$ at $37^{\circ} \mathrm{C}$. Quality of cDNA was assessed by using a PCR control run with human $\beta$-actin. Product bands were assessed by examination of agarose gel electrophoresis. Only samples that showed equal product bands at $330 \mathrm{bp}$ were included in this study.

Quantification of $m R N A$ Real-time quantitative PCR was performed using an ABI Prism 7900 Sequence Detection System (Applied Biosystems, Warrington, UK) and TaqMan Gene Expression Assays (Applied Biosystems) (Table 1). For TaqMan Gene Expression assays, the manufacturer's protocol with recommended 40 rounds of amplification was used. Thermal cycler conditions were $50^{\circ} \mathrm{C}$ for $2 \mathrm{~min}, 95^{\circ} \mathrm{C}$ for $10 \mathrm{~min}$, followed by $40 \times 95^{\circ} \mathrm{C}$ for $15 \mathrm{~s}$ and $60^{\circ} \mathrm{C}$ for $1 \mathrm{~min}$. Product melting curve analysis and gel electrophoresis experiments were used to ensure that only one product of the expected size was amplified.

Negative controls for each primer were included in each run. Quantitative values were obtained from the threshold cycle (Ct value) at which an increase in TaqMan probe fluorescent signal was associated with an exponential increase of each individual PCR product reaching a fixed threshold value. Each individual primer had a fixed threshold $C t$ value. These fixed threshold values were used for every cDNA sample (Table 1).

To enable comparison of different mRNA expression levels, their relation to the average expression level of housekeeping gene HPRT (hypoxanthine-guanine phosphoribosyltransferase) was evaluated. Data were analysed using the sequence detection software, which calculates the $C \mathrm{t}$ value. The expression of the target assay was normalised by subtracting the $C t$ value of the housekeeping gene from the $C t$ value of the relevant target assay. The fold increase, relative to the control, was obtained by using the formula $2^{-\Delta C t}$, and then expressed as a percentage $(\times 100)$. All samples were measured in duplicates.

Table I Intron-skipping primers used for real-time PCR, their fixed threshold Ct values and expression levels in different breast tissue

\begin{tabular}{|c|c|c|c|c|c|c|}
\hline Gene & $\begin{array}{l}\text { Gene expression } \\
\text { assay ID }\end{array}$ & $\begin{array}{c}\text { Threshold }(C t) \\
\text { value }\end{array}$ & $\begin{array}{l}\text { Expression } \\
\text { levels in } M\end{array}$ & $\begin{array}{l}\text { Expression } \\
\text { levels in NM }\end{array}$ & $\begin{array}{l}\text { Expression } \\
\text { levels in } \mathbf{N}\end{array}$ & $P$-values \\
\hline$S R C$ & Hs00I78494_ml & 0.28263707 & 9041 & 9252 & 9493 & 0.976 \\
\hline LYN & $\mathrm{Hs} 00176719 \mathrm{ml}$ & 0.34538345 & 7233 & 8922 & 10521 & 0.076 \\
\hline FYN & Hs00176628_ml & 0.27740355 & 2245 & 5293 & 25484 & $<0.001$ \\
\hline$F G R$ & $\mathrm{Hs} 00178340 \mathrm{ml}$ & 0.22993330 & 1144 & 1275 & 1072 & 0.943 \\
\hline HCK & Hs00 I76654_ml & 0.37934458 & 1815 & 2673 & 1712 & 0.070 \\
\hline HPRT & $4310890 \mathrm{E}$ & 0.25742040 & NA & NA & NA & NA \\
\hline
\end{tabular}

Abbreviations: $M=$ invasive breast cancer; $N=$ normal tissue; $N A=$ not applicable; $N M=$ non-malignant. The table reveals details of each individual Src kinase family member and the housekeeping gene HPRT. Expression levels of Src kinase family members in different breast tissue types are stated as medians. P-values express alterations of expression in the different breast tissue types (Kruskal-Wallis test). Bold typeface is used to highlight significant $P$-values. 


\section{Tissue microarray construction}

Tissue microarrays (TMAs) were already available for use in this study. The pathologist identified $0.6 \mathrm{~mm}^{2}$ cores of breast cancer tissue. The TMA blocks were constructed in triplicates (Tovey et al, 2005).

\section{Immunohistochemistry}

Staining for ER, PgR and HER2 had been previously performed for the cohort (Tovey et al, 2005). SFK member expression was investigated using antibodies for c-Src (36D10, Cell Signalling Technology, Danvers, MA, USA), Lyn (BD Biosciences, Oxford, UK) and Lck (Cell Signalling Technology). Ki67 antigen MIB-1 (DAKO, Ely, UK) was used to determine proliferation status. All SFK antibodies used were tested by western blot to ensure that only one single band of the appropriate size was observed. Tissue sections were dewaxed and rehydrated through graded alcohol. c-Src antibody was incubated in a preheated antigen retrieval solution (citrate buffer, $\mathrm{pH}$ 6.0, Vector Laboratories, Burlingame, CA, USA), whereas Lyn, Lck and Ki67 antibodies were incubated in TE Buffer ( $\mathrm{pH}$ 8.0, $5 \mathrm{~mm}$ Tris, VWR, Lutterworth, UK and $1 \mathrm{~mm}$ EDTA, Sigma, Dorset, UK). Antigen retrieval was performed by heating tissue sections under pressure for $5 \mathrm{~min}$ in a microwave. Endogenous peroxidase activity was destroyed by incubation in $0.3 \%$ hydrogen peroxide $\left(\mathrm{H}_{2} \mathrm{O}_{2}\right)(\mathrm{c}-\mathrm{Src}), 1 \% \mathrm{H}_{2} \mathrm{O}_{2}$ solution (Lyn) and $3 \% \mathrm{H}_{2} \mathrm{O}_{2}$ solution (Lck, Ki67), and non-specific binding blocked by incubating in 1.5\% normal horse serum (c-Src) and $5 \%$ normal horse serum (Lyn, Lck and Ki67) (Vector Laboratories) for $20 \mathrm{~min}$ at room temperature. Primary antibody was applied and tissue incubated with c-Src $\left(1: 200\right.$ dilution, $\left.4.32 \mu \mathrm{g} \mathrm{ml}^{-1}\right)$, Lck $\left(1: 50,0.76 \mu \mathrm{g} \mathrm{ml}^{-1}\right)$ and Ki67 $\left(1: 150,533.33 \mu \mathrm{g} \mathrm{ml}^{-1}\right)$ for $60 \mathrm{~min}$ at room temperature. Lyn was incubated overnight at $4^{\circ} \mathrm{C}(1: 5$, $\left.50 \mu \mathrm{g} \mathrm{ml}^{-1}\right)$. Signal was amplified and visualised using the DAKO Envision Kit (DAKO Cytomation, Glostrip, Denmark) and the chromagen 3,3'-diaminobenzidine (DAB, Vector Laboratories). Sections were counterstained, dehydrated and mounted. In each run, a positive control and a negative isotype-matched control was included to ensure no false-positive staining.

\section{Scoring}

The SFK member expression of each core (three per tumour specimen) was assessed using the weighted histoscore method ( $H$-score method (Kirkegaard et al, 2006)). Ki67 was scored counting positive and negative nuclei in the tumour specimen and then the percentage of positive cells was calculated (Ki67 labelling index (Canna et al, 2008)). Agreement between observers was excellent and measured in interclass correlation coefficient (ICCC). All ICCC scores were above 0.8 . The observers were blinded to the clinical outcome of the patients.

\section{Statistical analysis}

Differences in expression levels were analysed using the MannWhitney $U$-test or Kruskal-Wallis test, including a Wilcoxon-type test for trends, when appropriate. Associations between continuous variables were assessed with the Spearman rank test. Diseasespecific survival rates were generated using the Kaplan-Meier method. The log-rank test was used to compare significant differences between subgroups using univariate analysis. Multivariate stepwise Cox-regression analysis was performed to identify factors that were independently associated with disease-specific death. A stepwise backward procedure was used to derive a final model of the variables that had a significant independent relationship with survival. To remove a variable from the model, the corresponding $P$-value had to be $>0.05$.

Inter-relationships between clinical parameters, ER, PgR and HER2 status were calculated using the $\chi^{2}$-test. Because of the number of statistical comparisons, a $P$-value of $<0.01$ was considered to be significant. Data are expressed as median and range. The statistical analyses were performed using a statistical software package (SPSS 15.0 Inc, Chicago, IL, USA).

\section{RESULTS}

\section{Clinicopathological details of cohort one}

The PCR cohort consisted of 81 invasive breast cancers (M), 48 non-malignant (NM) and 10 normal $(\mathrm{N})$ breast tissue samples. Median age of the breast cancer patients was 61 years (IQR 49-74). Median size of breast cancer was $30 \mathrm{~mm}$ (IQR 20-42). In all, $40 \%$ of the specimens were pathologically graded G2 and 48\% G3. A total of 52 breast cancer patients were ER positive compared with 29 ER-negative patients. A total of $55 \%$ of breast cancer patients were axillary lymph node positive. Median NPI was 4.6 (IQR 4.3-5.4). Patients underwent either breast-conserving wide local excision $(16 \%)$ or a radical mastectomy $(67 \%$; the rest $17 \%$ unknown). Axillary dissection was performed in $83 \%$ of cases. At time of analysis, 37 out of 79 patients were deceased. Of those 37 patients, 18 died of breast cancer-related causes. Median follow-up time was 5.6 years (IQR $1.8-17.6$ ).

Median age of breast cancer patients, from whom a nonmalignant specimen of breast tissue was obtained, was also 61 years (IQR $52-71$ ). Of those patients, $63 \%$ were ER positive and $17 \%$ ER negative. ER status was not significantly different between tissue types $(P=0.847)$. Median age of breast reduction patients supplying normal breast tissue was 37 years (IQR 33-48).

\section{mRNA expression levels in human breast tissue}

Expression levels for SFK member were quantified in all tissue samples (Table 1). BLK was the least-expressed SFK member in all breast tissues. No change in the level of $S R C$ expression was observed between tissue types $(P=0.976)$ (Figure $1 \mathrm{~A})$, whereas $L C K, F Y N$ and YES showed significant changes in expression between different breast tissue types (Table 1). Figure $1 \mathrm{~A}-\mathrm{H}$ demonstrates the data range of all SFK members.

SFK member expression in breast cancer specimens The most highly expressed SFK members in malignant breast tissue were $S R C$ and $L Y N$. Higher expression levels of $L C K$ were observed in invasive breast cancers compared with non-malignant and normal breast tissue $(P<0.001)$ (Figure 1C). Interestingly, LCK was 14 -fold less expressed than $S R C$. It also was the only SFK member that showed a difference in expression levels between ER-negative and ER-positive patients. LCK was more highly expressed in ER-negative patients, compared with ER-positive patients (Figure 2A). All SFK members correlated with SRC expression. The strongest correlation with $S R C$ expression was detected with $L Y N(P<0.001$, c.c. 0.570$)$ and the weakest with $Y E S(P=0.030$, c.c. 0.242$)$. Survival analysis was completed for all SFK members. Only $S R C$ was significantly associated with decreased disease-specific survival in ER-positive breast cancer patients $(P=0.012$; Figure $2 \mathrm{~B})$ compared with ER-negative patients $(P=0.923$, Figure $2 \mathrm{C})$. Patients with high $S R C$ mRNA expression had a median survival of 4.5 years (IQR 2.7-6.3) compared with those with low expression, with a median survival of 11.6 years (IQR $6.9-13.3)(P=0.012)$.

SFK member expression in non-malignant breast tissue As observed within the invasive breast cancer specimen, SRC and LYN were the highest-expressed SFK members in non-malignant breast tissue. YES was least expressed in non-malignant breast tissue, compared with malignant and normal breast tissue $(P<0.001)$ (Figure $1 \mathrm{H}$ ). As with the invasive breast cancer specimens, all other SFK members correlated with $S R C$ expression. Again the strongest $S R C$ expression correlation was with $L Y N(P<0.001$, c.c. 0.799) (Figure 2D) and the weakest with YES ( $P=0.027$, c.c. 0.326$)$. 

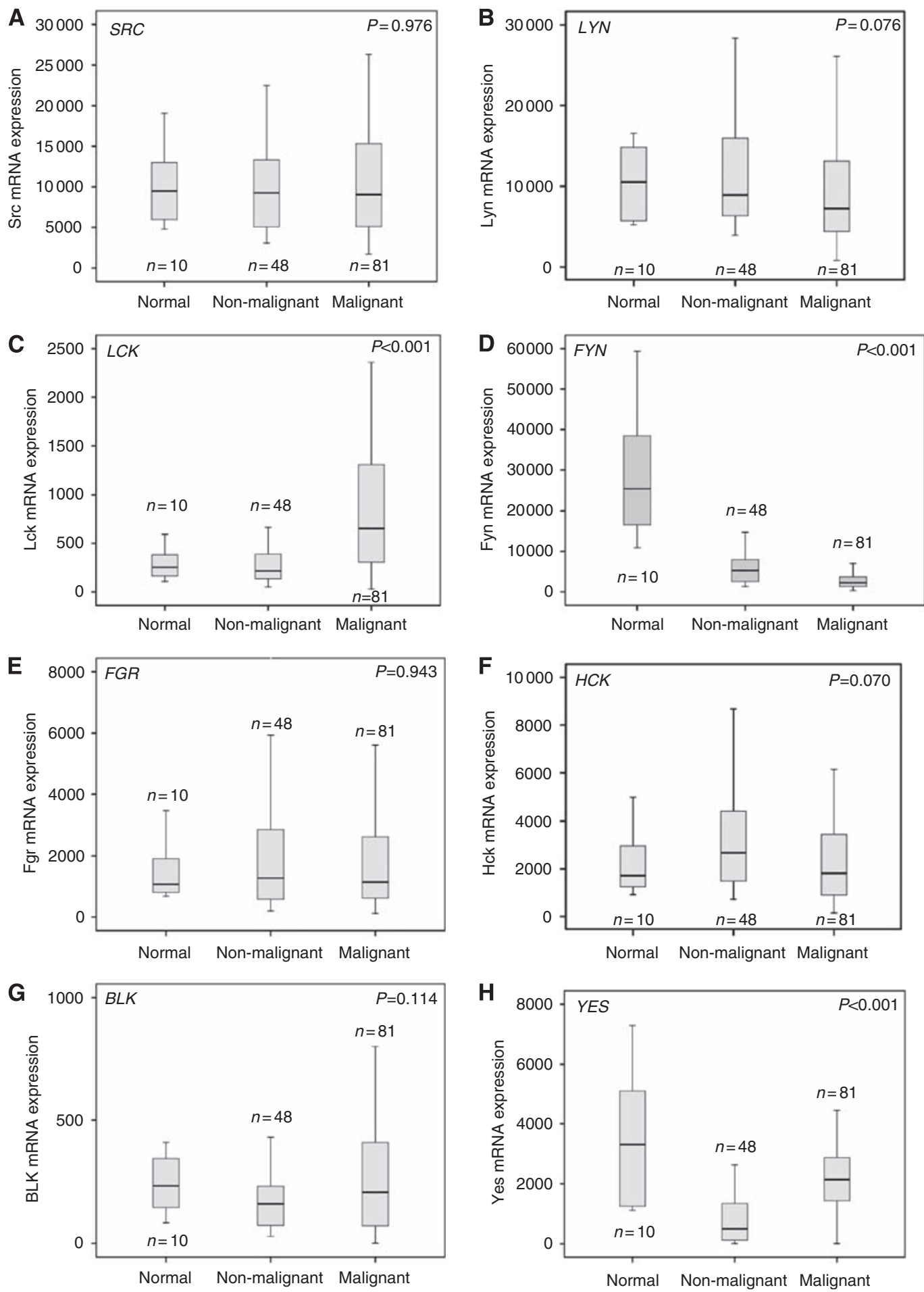

Figure I Graphs for cohort one (mRNA). (A-H) mRNA expression of Src kinase family members in different breast tissue. (A) Unchanged SRC mRNA expression levels in normal, non-malignant and malignant breast specimens $(P=0.907)$. (B) LYN mRNA expression levels in normal, non-malignant and malignant breast specimens $(P=0.076)$. (C) Different $L C K$ mRNA expression in normal, non-malignant and malignant breast specimens $(P<0.00 \mathrm{I})$. (D) Altered FYN mRNA expression levels in normal, non-malignant and malignant breast specimens $(P<0.00 \mathrm{I})$. (E) FGR mRNA expression levels in normal, non-malignant and malignant breast specimens $(P=0.943)$. (F) HCK mRNA expression levels in normal, non-malignant and malignant breast specimens $(P=0.070)$. (G) BLK mRNA expression levels in normal, non-malignant and malignant breast specimens $(P=0.1 \mid 4)$. (H) YES mRNA expression in normal, non-malignant and malignant breast specimens $(P<0.00 \mathrm{I})$.

SFK member expression in normal/breast reduction tissue FYN was the most highly expressed SFK member in normal tissue. It was significantly higher expressed than any other SFK members: 2.7-fold higher than SRC and 100-fold higher than LCK. Highest expression levels of $F Y N$ were observed in normal tissue compared with non-malignant and lowest in invasive breast cancer specimens $(P<0.001)$ (Figure 1D). No correlations between SRC and SFK members were observed in normal breast tissue. 

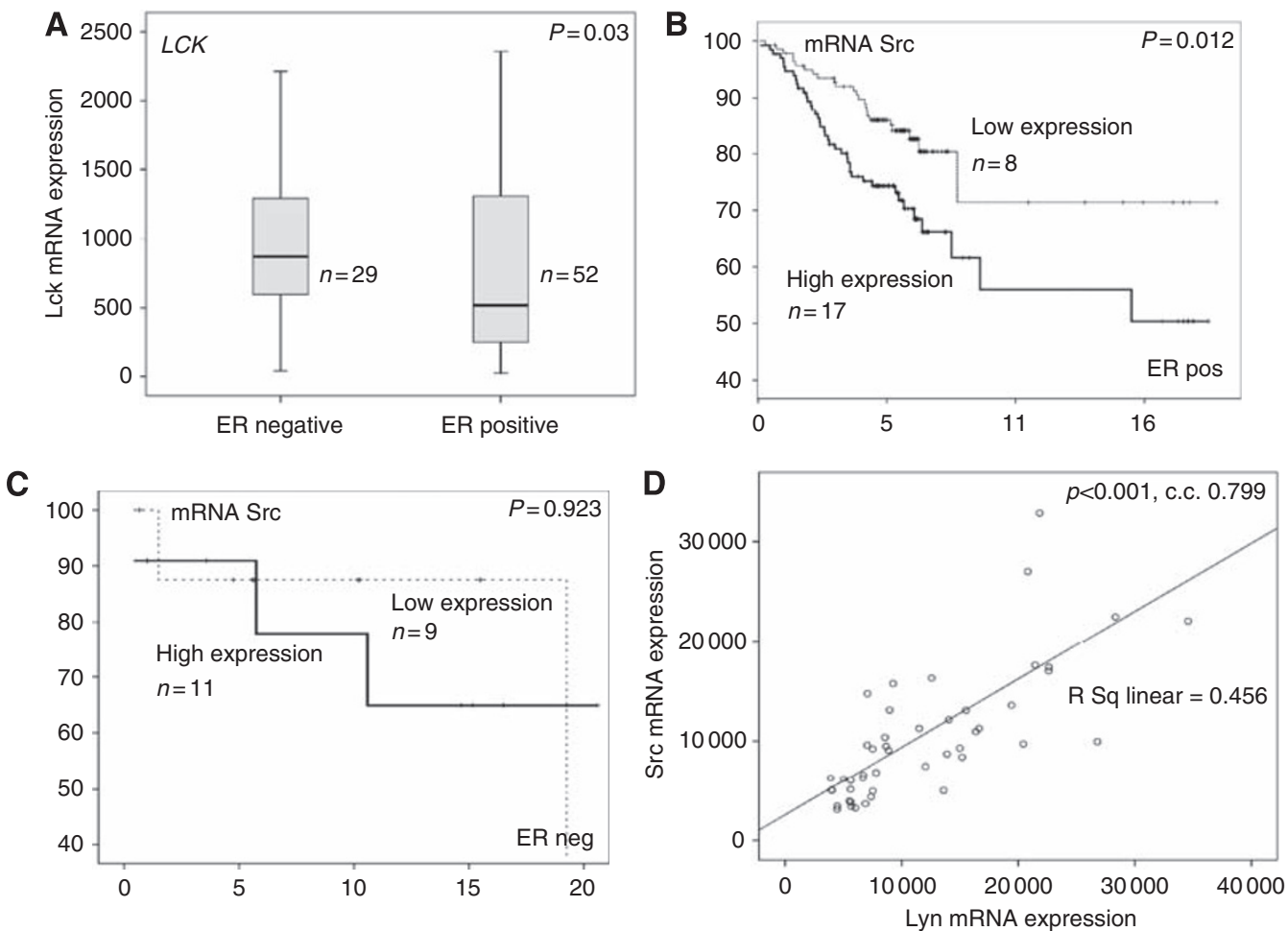

Figure 2 (A) The difference between LCK mRNA expression in ER-negative compared with ER-positive breast cancer patients $(P=0.030)$. (B) A Kaplan-Meier survival graph for mRNA expression of SFK member SRC in ER-positive patients $(P=0.012)$. (C) A Kaplan-Meier survival graph for mRNA expression of SFK member SRC in ER-negative patients $(P=0.923)$. (D) The correlation of SRC mRNA expression with LYN in the non-malignant PCR cohort $(P<0.00$ I, c.c. 0.799).

Table 2 Impact of clinicopathological factors and protein expression/activation on patient survival

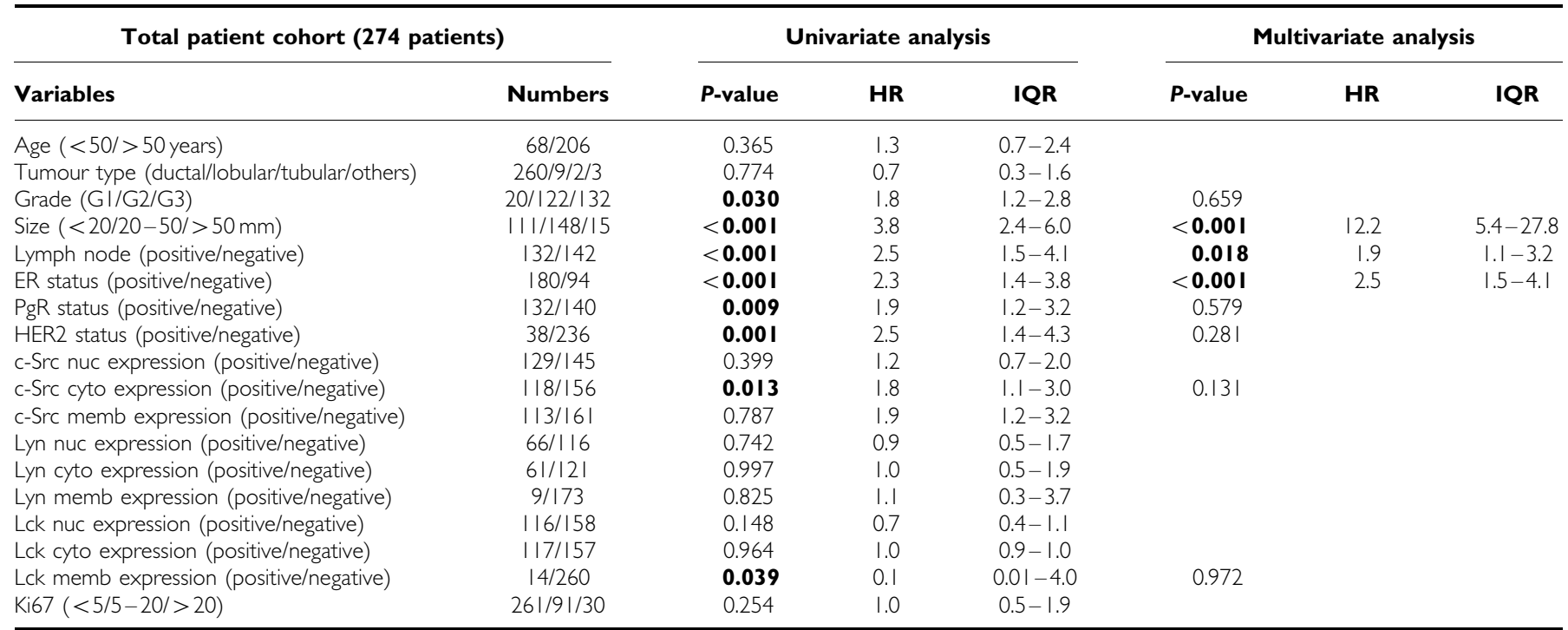

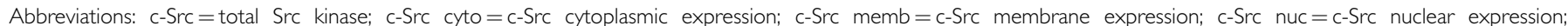
ductal=ductal carcinoma; ER=oestrogen receptor; Grade=Bloom and Richardson grade; HER2=human epidermal growth factor receptor 2; HR=hazards ratio; $\mathrm{IQR}=$ interquartile range; Ki67 = Ki67 proliferation score, low <5, moderate 5-20, high > 20; Lck cyto = Lck cytoplasmic expression; Lck memb = Lck membrane expression; Lck nuc = Lyn nuclear expression; Lyn cyto = Lyn cytoplasmic expression; Lyn memb = Lyn membrane expression; Lyn nuc = Lyn nuclear expression; others = mucinous, mucoid and micropapillary carcinoma; $\mathrm{PgR}=$ progesterone receptor; tubular = tubular carcinoma. The table shows an overview of the full patient cohort's characteristics. Each clinical and pathological parameter was correlated to disease-specific survival ( $P$-values). Bold typeface is used to highlight significant $P$-values.

\section{Clinicopathological details of cohort two}

The second cohort consisted of 274 breast cancer patients (180 ER positive and 94 ER negative) (Table 2). Median age was 58 years
(IQR 51-68). Median tumour size was $20 \mathrm{~mm}$ (IQR 15-30). Majority of the cancer specimens were pathologically graded as G2 (45\%) and G3 (48\%). A total of $49 \%$ of the patients were axillary lymph node positive. Mean patient follow-up was 6.3 years 
(minimum follow-up was 3.7 years and the maximum follow-up was 19.5 years). A total of 17 patients were lost to follow-up. During this period, 65 patients died of their cancer and a further
27 patients died of inter-current disease. In all, 171 patients were still alive at time of last follow-up. Correlations between the clinicopathological characteristics of this cohort are shown in Table 2.
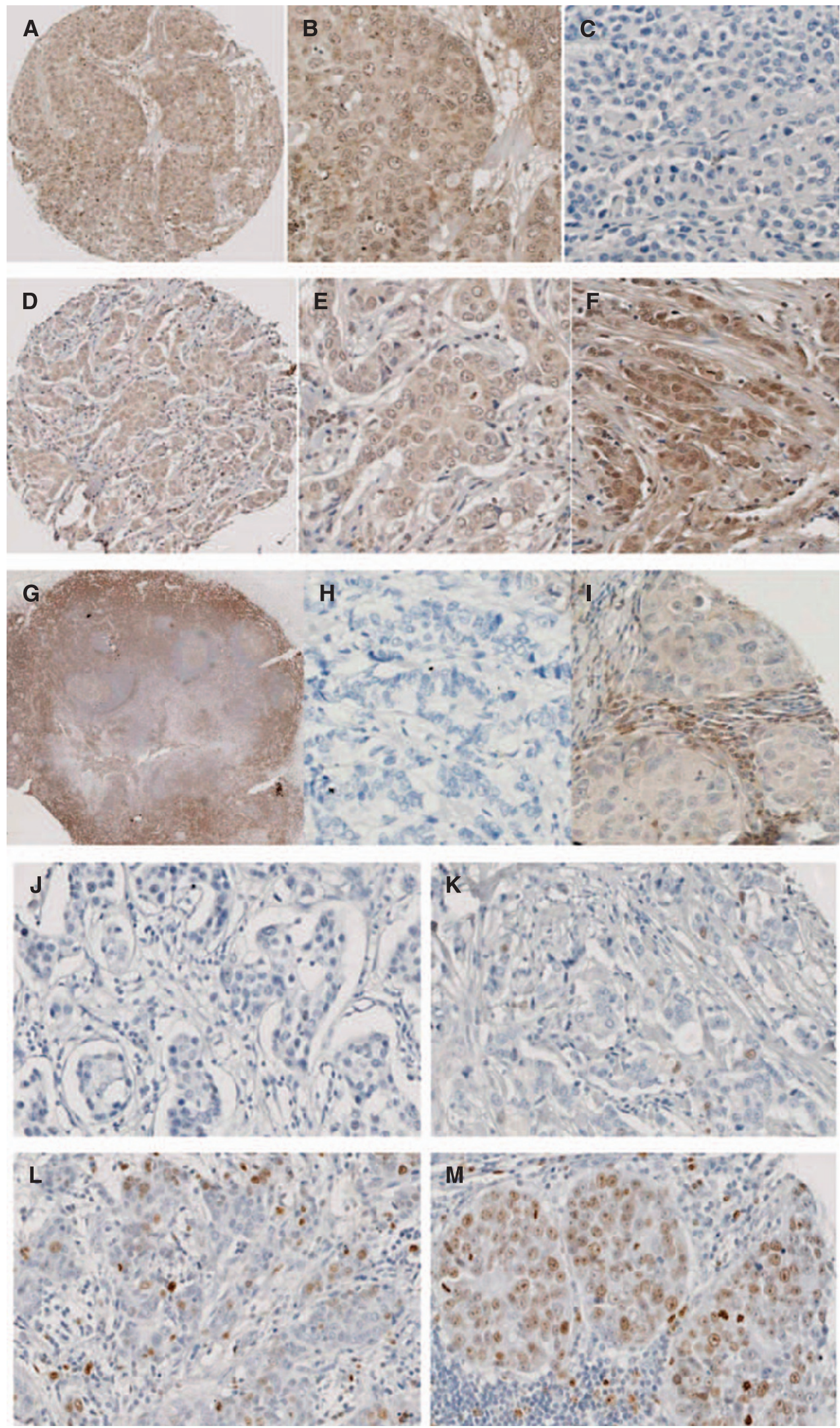


\section{Protein expression levels of SFK members in invasive} breast cancers

c-Src kinase Each cellular location was independently assessed for Src kinase expression levels. A total of $48 \%$ of tumours exhibited nuclear expression, $61 \%$ cytoplasmic and $41 \%$ membrane (Figure $3 \mathrm{~A}-\mathrm{C}$ ). Tumours were subdivided into those with high (above the median) or low (below or equal to the median) expression. The $\chi^{2}$-analysis demonstrated that grade and HER2 status positively correlated with cytoplasmic c-Src expression (Table 3). The ER and PgR status correlated negatively with cytoplasmic and membrane c-Src expression (Table 3). c-Src expression at each cellular location correlated with HER2 status (Table 3) and with each other (Table 4). On univariate analysis, neither membrane nor nuclear
c-Src expression was associated with disease-specific survival. High cytoplasmic c-Src kinase expression was significantly associated with shorter disease-specific survival $(P=0.013$; Figure $4 \mathrm{~A})$, but was not independent in multivariate analysis (Table 2). Those patients with high cytoplasmic c-Src expression had a median survival of 12.2 years (IQR 10.0-14.4) compared with those with low expression, with median survival of 15.6 years (IQR 13.9-17.3).

Lyn Owing to tissue limitations, only $68 \%$ of the tumours previously available for analysis were able to be stained for Lyn expression (186 of 274). A total of $34 \%$ of Lyn expression was observed in the nucleus, $36 \%$ in the cytoplasm and only $5 \%$ in the membrane (Figure 3D-F). On univariate analysis, there was no association noticed between Lyn expression and disease-specific

Table 3 The interrelationships between the clinicopathological characteristics of patients with breast cancer, Src kinase family member expression and Ki67

\begin{tabular}{|c|c|c|c|c|c|c|c|c|c|c|c|}
\hline \multicolumn{2}{|c|}{ Total patient cohort ( 274 patients) } & \multicolumn{10}{|c|}{$\chi^{2} P$-values } \\
\hline Variables & Numbers & $\begin{array}{l}\text { c-Src } \\
\text { nuc }\end{array}$ & $\begin{array}{l}\text { c-Src } \\
\text { cyto }\end{array}$ & $\begin{array}{c}\text { c-Src } \\
\text { memb }\end{array}$ & $\begin{array}{l}\text { Lyn } \\
\text { nuc }\end{array}$ & $\begin{array}{l}\text { Lyn } \\
\text { cyto }\end{array}$ & $\begin{array}{c}\text { Lyn } \\
\text { memb }\end{array}$ & $\begin{array}{l}\text { Lck } \\
\text { nuc }\end{array}$ & $\begin{array}{l}\text { Lck } \\
\text { cyto }\end{array}$ & $\begin{array}{l}\text { Lck } \\
\text { memb }\end{array}$ & Ki 67 \\
\hline Age $(<50 />50$ years $)$ & $68 / 206$ & 0.786 & 0.638 & 0.798 & 0.259 & 0.027 & 0.297 & 0.639 & 0.927 & 0.024 & 0.965 \\
\hline Tumour type (duct/lob/tub/others) & $260 / 9 / 2 / 3$ & 0.788 & 0.431 & 0.446 & 0.642 & 0.547 & 0.492 & 0.375 & 0.032 & 0.842 & 0.360 \\
\hline Grade $(\mathrm{Gl} / \mathrm{G} 2 / \mathrm{G} 3)$ & $20 / 122 / 132$ & 0.021 & 0.001 & 0.017 & 0.019 & 0.632 & 0.991 & 0.034 & 0.543 & 0.741 & 0.006 \\
\hline Size $(<20,20-50,>50 \mathrm{~mm})$ & $111 / 148 / 15$ & 0.421 & 0.037 & 0.007 & 0.029 & 0.832 & 0.115 & 0.892 & 0.580 & 0.926 & 0.186 \\
\hline PgR status (positive/negative) & $132 / 140$ & 0.184 & $0.002^{\mathrm{a}}$ & $0.00 I^{a}$ & 0.339 & 0.015 & 0.048 & 0.097 & 0.036 & 0.090 & 0.280 \\
\hline HER2 status (positive/negative) & $38 / 236$ & 0.007 & $<0.001$ & 0.007 & 0.733 & 0.836 & 0.772 & 0.168 & 0.085 & 1.000 & 0.200 \\
\hline
\end{tabular}

Abbreviations: c-Src = total Src kinase; c-Src cyto =c-Src cytoplasmic expression; c-Src memb =c-Src membrane expression; c-Src nuc =c-Src nuclear expression; duct = ductal carcinoma; $\mathrm{ER}=$ oestrogen receptor; Grade = Bloom and Richardson grade; HER2 = human epidermal growth factor receptor 2; Ki67 = Ki67 proliferation score, low <5, moderate 5-20, high >20; Lck cyto = Lck cytoplasmic expression; Lck memb = Lck membrane expression; Lck nuc = Lyn nuclear expression; lob = lobular carcinoma; Lyn cyto = Lyn cytoplasmic expression; Lyn memb = Lyn membrane expression; Lyn nuc = Lyn nuclear expression; others = mucinous, mucoid and micropapillary carcinoma; tub = tubular carcinoma. ${ }^{a}$ Negative correlation. Bold typeface is used to highlight significant $P$-values.

Table 4 The interrelationships between Src kinase family member expression and Ki67

\begin{tabular}{|c|c|c|c|c|c|c|c|c|c|c|}
\hline \multicolumn{2}{|c|}{ Total patient cohort ( 274 patients) } & \multicolumn{9}{|c|}{$\chi^{2} P$-values } \\
\hline Variables & Numbers & $\begin{array}{l}\text { c-Src } \\
\text { cyto }\end{array}$ & $\begin{array}{l}\text { c-Src } \\
\text { memb }\end{array}$ & $\begin{array}{l}\text { Lyn } \\
\text { nuc }\end{array}$ & $\begin{array}{l}\text { Lyn } \\
\text { cyto }\end{array}$ & $\begin{array}{c}\text { Lyn } \\
\text { memb }\end{array}$ & $\begin{array}{l}\text { Lck } \\
\text { nuc }\end{array}$ & $\begin{array}{l}\text { Lck } \\
\text { cyto }\end{array}$ & $\begin{array}{c}\text { Lck } \\
\text { memb }\end{array}$ & Ki67 \\
\hline c-Src nuc (positive/negative) & $129 / 145$ & $<0.001$ & $<0.001$ & 0.163 & 0.646 & 0.917 & 0.328 & 0.461 & 0.701 & 0.001 \\
\hline c-Src cyto (positive/negative) & $118 / 156$ & & $<\mathbf{0 . 0 0 1}$ & 0.621 & 0.579 & 0.780 & 0.299 & 0.508 & 0.934 & 0.110 \\
\hline c-Src memb (positive/negative) & $113 / 16 \mid$ & & & 0.691 & 0.497 & 0.410 & 0.274 & 0.064 & 0.017 & 0.110 \\
\hline Lyn nuclear (positive/negative) & $66 / 116$ & & & & $<0.001$ & 0.345 & 0.016 & 0.975 & 0.534 & 0.081 \\
\hline Lck nuclear (positive/negative) & $116 / 158$ & & & & & & & $<\mathbf{0 . 0 0 1}$ & 0.001 & 0.045 \\
\hline Lck cyto (positive/negative) & $117 / 157$ & & & & & & & & $<\mathbf{0 . 0 0 1}$ & 0.572 \\
\hline Lck memb (positive/negative) & $14 / 260$ & & & & & & & & & 0.506 \\
\hline
\end{tabular}

Abbreviations: c-Src = total Src kinase; c-Src cyto =c-Src cytoplasmic expression; c-Src memb =c-Src membrane expression; duct = ductal carcinoma; c-Src nuc =c-Src nuclear expression; Grade = Bloom and Richardson grade; Ki67 = Ki67 proliferation score low < 5, moderate 5-20, high > 20; Lck cyto = Lck cytoplasmic expression; Lck memb = Lck membrane expression; Lck nuc = Lyn nuclear expression; lob = lobular carcinoma; tub = tubular carcinoma; Lyn cyto = Lyn cytoplasmic expression; Lyn memb = Lyn membrane expression; Lyn nuc = Lyn nuclear expression; others = mucinous, mucoid and micropapillary carcinoma. Bold typeface is used to highlight significant $P$-value.

Figure 3 Images of immunohistochemistry $(\mathrm{IHC})$ for each antibody. (A-C) Breast cancer tissue stained with c-Src antibody (I :200, Cell Signalling). (A) An overview of a $0.6 \mathrm{~mm}$ core of the breast cancer tissue microarray, demonstrating no stromal staining, weak cytoplasmic, none and weak nuclear staining; magnification $\times 10$. (B) Weak cytoplasmic, none and weak nuclear and weak membrane staining; magnification $\times 100$. (C) Negative staining of stroma and tumour tissue; magnification $\times 100$. (D-F) Breast cancer tissue stained with Lyn antibody (I:5, BD Biosciences). (D) An overview of a $0.6 \mathrm{~mm}$ core of the breast cancer tissue microarray, demonstrating no stromal staining, weak cytoplasmic, none and weak nuclear staining; magnification $\times$ 10. (E) Weak cytoplasmic, none and weak nuclear staining; magnification $\times 100$. (F) No stromal staining, weak cytoplasmic, none, weak and moderate nuclear staining; magnification $\times 100$. (G-I) Breast cancer tissue stained with Lck antibody (I :50, Cell Signalling). (G) Strong staining of tonsil with Lck (positive control); magnification $\times 2$. $(\mathbf{H})$ Negative staining of stroma and tumour tissue; magnification $\times 100$. (I) Weak cytoplasmic and weak membrane staining; magnification $\times 100$. (J-M) Ki67 staining of invasive breast cancer specimen ( I I 50, DAKO). (J) Negative staining of stroma and tumour tissue; magnification $\times 100$. (K) Ki67 staining classified as weak staining; magnification $\times 100$. (L) Ki67 staining classified as moderate staining; magnification $\times 100$. (M) Ki67 staining classified as strong staining; magnification $\times 100$. 

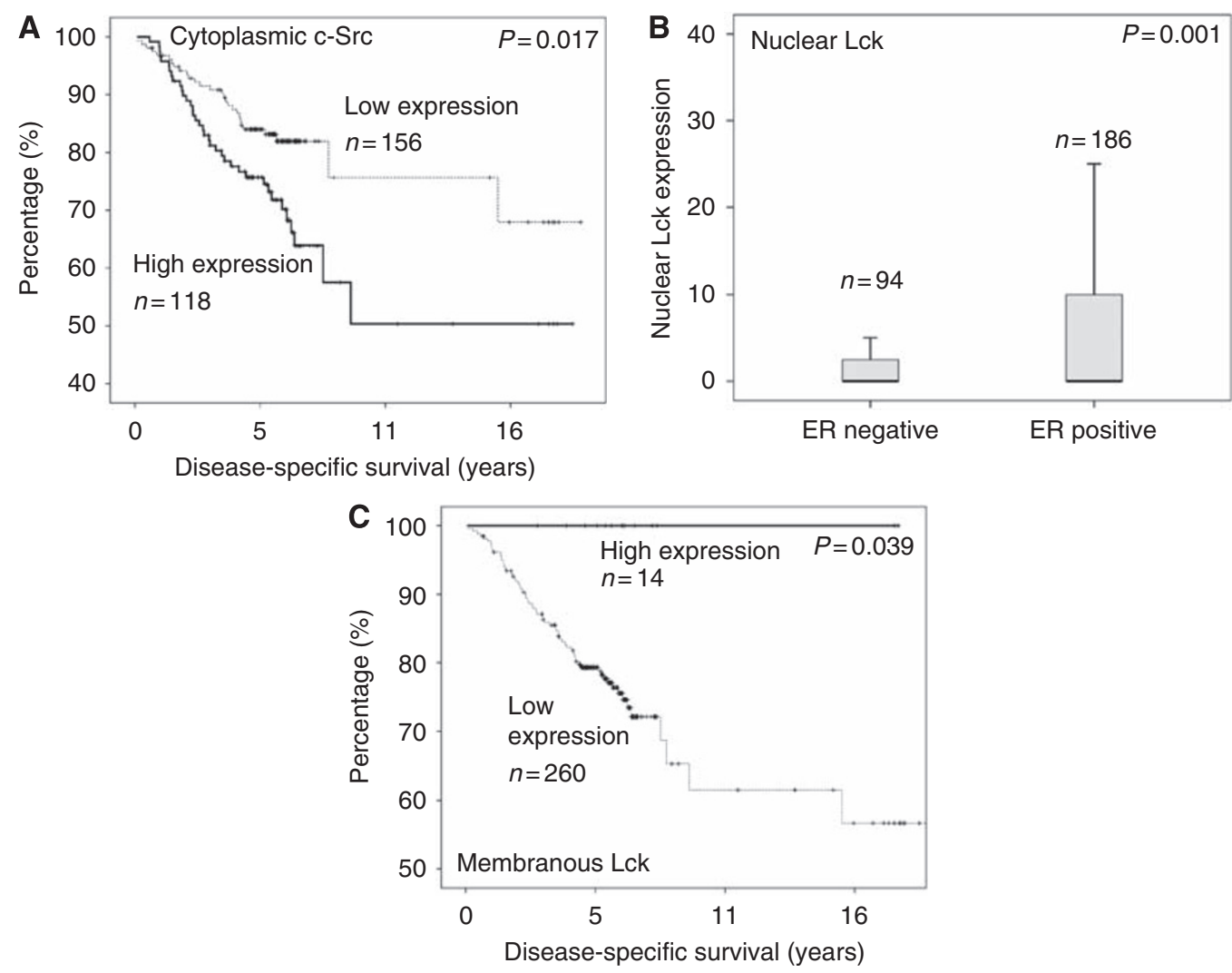

Figure 4 Kaplan-Meier survival graphs for Src kinase family member expressions in cohort two/lHC cohort $(n=274)$. (A) Kaplan-Meier survival graph for cytoplasmic c-Src $(P=0.013)$. (B) Boxplot displaying nuclear Lck protein expression difference in ER-negative and -positive breast cancer patients $(P=0.00$ I). $(\mathbf{C})$ Kaplan-Meier survival graph of membranous Lck $(P=0.039)$.

survival at any cellular location (Table 2 ). The $\chi^{2}$-analysis showed no significant correlations between Lyn expression, clinicopathological features of the cohort or expression level and location of other SFK members (Tables 3 and 4).

Lck Lck expression was observed to be $42.5 \%$ in the breast cancers nucleus, $42.5 \%$ in the cytoplasm and $5 \%$ in the membrane (Figure $3 \mathrm{G}-\mathrm{I}$ ). The $\chi^{2}$-analysis showed that nuclear Lck expression correlated negatively with ER status $(P=0.001$; Table 3 , Figure $4 \mathrm{~B})$. Lck expression at all cellular locations correlated with each other. On univariate analysis, cytoplasmic and nuclear Lck expression was not associated with disease-specific survival (Table 2), whereas membrane Lck expression was significantly associated with disease-specific survival $(P=0.039$; Figure $4 \mathrm{C})$. None of patients expressing Lck on the cell membrane died of breast cancer. Median follow-up for patients with positive Lck staining of the membrane was 7.8 years (s.d. \pm 4.5 ) and for patients without staining, 6.0 years (s.d. \pm 3.5$)$.

Ki67 As observed before with Lyn, Ki67 immunohistochemistry was obtained from $71 \%$ (194 of 274) of the TMA tumours because of tissue limitation. Median Ki67 score was 3.8 (IQR 0-9.8). Scores were classified into three groups (low-medium-high). A total of $59 \%$ of the tumour specimens had a low proliferation rate, with a Ki67 score of $<5,32 \%$ had a medium proliferation rate of $5-20$ and only $9 \%$ of the tumours had a high proliferation rate of $>20$ (Figure $3 \mathrm{~J}-\mathrm{M}$ ). The $\chi^{2}$-analysis demonstrated that Ki67 scores correlated positively with tumour grade (Table 3 ) and nuclear c-Src $(P=0.001)$. On univariate analysis, Ki67 score was not associated with disease-specific survival.

The relationship between all family members and clinical parameters is shown in Figure 5.

\section{DISCUSSION}

The SFK members are expressed in various cell types and tissues (Irby and Yeatman, 2000) and involved in cancer progression, via transduction of signals for cell growth, differentiation and survival, influencing cellular adhesion, migration and invasion (Brown and Cooper, 1996). However, there is little translational evidence of SFK member expression in breast tissue. We have investigated expression levels for eight SFK members in normal, non-malignant and malignant breast tissue. Interestingly, $S R C$ expression levels were unchanged between the tissue types, despite being the highest-expressed SFK member in malignant and non-malignant, but not in normal breast tissue. SRC also was the only SFK member that was significantly associated with patients' survival. Owing to small patient numbers in the PCR cohort, the study to investigate the role of Src was expanded into a larger cohort of formalin-fixed paraffin-embedded specimens (IHC cohort). High expression of cytoplasmic c-Src was associated with shorter disease-specific survival, increasing grade, tumour size, ER negativity and HER2 positivity. These findings are consistent with our previous results (Elsberger et al, 2009), with c-Src being associated with more aggressive growth in cancer cell lines (Hynes, 2000; Frame, 2002). We observed that Ki67 proliferation index correlated positively with c-Src nuclear expression, but not with c-Src cytoplasmic expression. This suggests that $\mathrm{c}$-Src may have multiple roles within the cell depending on cellular location. It was not surprising to find that Ki67 was positively correlating with grade of the breast cancers.

$L Y N$ was also expressed at high mRNA levels in $\mathrm{M}$ and NM tissue. However, no associations with clinicopathological features and survival were noted in both cohorts. Other studies report that Lyn has a part in developing chemoresistance of colon cancer (Bates et al, 2001), progression of prostate tumours (Park et al, 2008) 


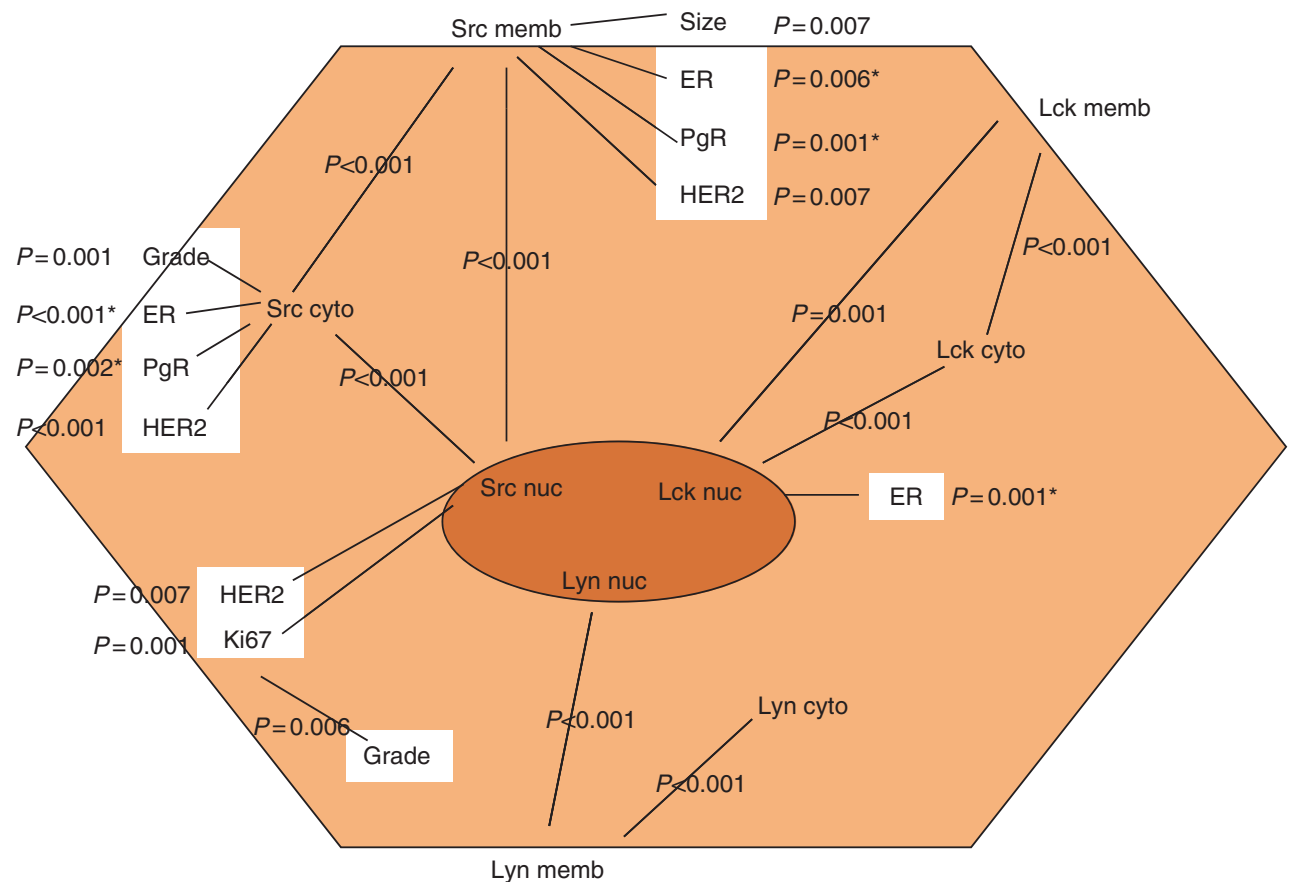

Figure 5 Schematic representation of correlations between clinicopathological features of the $\amalg \mathrm{HC}$ cohort, SFK protein expression and cellular location.

and leukaemia (Lee et al, 2008). The latter is not surprising, as Lyn is associated with a number of haematopoietic cell surface receptors, cytokine receptors and is a key mediator in several pathways of B-cell activation (Hibbs and Dunn, 1997). These observations are congruent with a role for Lyn associated with the development of chemoresistance. This study does not use any hormone-resistant or chemoresistant tumours; only tumours obtained at primary diagnosis. In the RT-PCR cohort, LCK mRNA expression in invasive breast cancer was 14 -fold less than $S R C$ and was associated with improved disease-specific survival in the IHC cohort. Surprisingly, this was reverse to the observation made with c-Src. Lck membrane expression was not associated with patient mortality. A similar immunohistochemistry study (Elsberger et al, 2009), investigating the different phosphorylation sites of Src, demonstrated that phosphorylation site Y215 was associated with improved disease-specific survival. With the knowledge that phosphorylation antibodies are able to detect other SFK members, we hypothesise that the Y216Src antibody used could have identified Lck as the other SFK member associated with good clinical outcome. However, this observation with Lck membrane expression and good prognosis was only observed in a small number of patients. Therefore, further analysis in a much larger cohort is required to verify these results.

LCK mRNA expression was found to be higher in ER-negative compared with ER-positive breast cancer samples. This was not reproducible in the IHC cohort. Nuclear Lck protein expression was higher expressed in the ER-positive breast cancer patients. Interestingly, survival analysis with high nuclear Lck expression displayed a trend to better clinical outcome of ER-positive compared with ER-negative patients within the first 5 years after diagnosis (data not shown). These findings are consistent with results reported by Rody et al (2009), showing that Lck was associated with improved disease-free survival within the ER-positive and ER/HER2-positive breast cancer subgroup. It is unclear whether this discrepancy between mRNA and protein expression is based on using different patient cohorts or altered transcription from RNA level to protein synthesis and expression.

As Lck is known to be involved in T-cell proliferation (Palacios and Weiss, 2004), it was hypothesised that expression of this gene was linked with the presence of lymphocyte infiltration within the tumour and interacting with it. Results of this study demonstrated that Lck is expressed within the tumour, providing evidence that Lck itself may be involved with signal transduction in the tumour. Other studies suggest that Syk, a member of another non-receptor tyrosine family, is involved in hypoxia-driven tumour progression via cross-talk to Lck in the nucleus (Chakraborty et al, 2006).

Lck has been implicated in the mitochondrial apoptosis pathway by controlling the expression of pro-apoptotic factor Bak (Samraj et al, 2006). Cell line experiments have shown that Lck deficiency resulted in resistance to anticancer drug-induced apoptosis. T-lymphoma cells lacking Lck have shown marked resistance to apoptosis reduction on exposure to ionising radiation (Belka et al, 1999). A more recent study from the same group adjusted their previous findings that not just the lack of Lck caused pronounced apoptosis resistance in response to stimuli of the intrinsic pathway but the additional loss of Bak was responsible for reduced sensitivity (Rudner et al, 2009). Decreased levels of other pro-apoptotic Bcl-2 family members, for example, Bax, have been shown to correspond to shorter survival in women with metastatic breast cancer. However, as yet no significant correlation between Bak and clinical outcome has been seen within breast cancer (Reed, 1999).

This study established that all SFK members were expressed in normal, non-malignant and malignant breast tissue. Quantitative real-time PCR results showed equal SRC mRNA expression within the different breast tissue types. However, this method does not provide details regarding cellular location of Src kinase. Despite two dissimilar cohorts of breast cancer patients and different investigation methods, Src kinase was associated with poorer survival outcome.

One major problem still remains: how to assess which tumours will respond to Src inhibitors, so that those patients can be selected who will probably benefit most from the treatment. Applicability of microarray gene analysis in the clinical setting is now being tested after identifying a gene signature that was able to predict response to dasatinib in cell lines (Huang et al, 2007). Response rate with molecular target therapy in unselected patient groups have been very modest so far, and this most likely indicates that in most solid tumours no single molecular event drives tumourigensis. The need 
for new predictive and prognostic indicators is clear, especially in the currently difficult-to-treat patient subgroups such as ER/PgRnegative and/or HER2-positive patients. The results of this study highlight an exciting area for future research in terms of predicting survival and the mechanisms of how this occurs.

\section{ACKNOWLEDGEMENTS}

We thank The Royal College of Surgeons Edinburgh, The Royal College of Physicians and Surgeons Glasgow, GRI endowment and Tenovus committee for their financial support. Tissue specimens for RT-PCR were kindly supplied by Tissue Bank Glasgow (GGCNHS-Bio). Tissue microarrays were constructed by Sylvia Brown. This study was supported by the Glasgow Royal Endowment and Tenovus Grant, the Royal College of Surgeons Edinburgh and the Royal College of Physicians and Surgeons Glasgow.

\section{Conflict of Interest}

The authors declare no conflict of interest.

\section{REFERENCES}

Bates RC, Edwards NS, Burns GF, Fisher DE (2001) A CD44 survival pathway triggers chemoresistance via lyn kinase and phosphoinositide 3-kinase/Akt in colon carcinoma cells. Cancer Res 61: 5275-5283

Belka C, Marini P, Lepple-Wienhues A, Budach W, Jekle A, Los M, Lang F, Schulze-Osthoff K, Gulbins E, Bamberg M (1999) The tyrosine kinase lck is required for CD95-independent caspase-8 activation and apoptosis in response to ionizing radiation. Oncogene 18: 4983-4992

Bolen JB, Veillette A, Schwartz AM, DeSeau V, Rosen N (1987) Activation of pp60c-src protein kinase activity in human colon carcinoma. Proc Natl Acad Sci USA 84: 2251-2255

Brown MT, Cooper JA (1996) Regulation, substrates and functions of src. Biochim Biophys Acta 1287: 121 - 149

Campbell EJ, McDuff E, Tatarov O, Tovey S, Brunton V, Cooke TG, Edwards J (2008) Phosphorylated c-Src in the nucleus is associated with improved patient outcome in ER-positive breast cancer. Br J Cancer 99: $1769-1774$

Canna K, Hilmy M, McMillan DC, Smith GW, McKee RF, McArdle CS, McNicol AM (2008) The relationship between tumour proliferative activity, the systemic inflammatory response and survival in patients undergoing curative resection for colorectal cancer. Colorectal Dis 10: $663-667$

Chakraborty G, Rangaswami H, Jain S, Kundu GC (2006) Hypoxia regulates cross-talk between Syk and Lck leading to breast cancer progression and angiogenesis. J Biol Chem 281: 11322-11331

Choi YL, Bocanegra M, Kwon MJ, Shin YK, Nam SJ, Yang JH, Kao J, Godwin AK, Pollack JR (2010) LYN is a mediator of epithelialmesenchymal transition and a target of dasatinib in breast cancer. Cancer Res 70: 2296-2306

Elsberger B, Tan BA, Mitchell TJ, Brown SB, Mallon EA, Tovey SM, Cooke TG, Brunton VG, Edwards J (2009) Is expression or activation of Src kinase associated with cancer-specific survival in ER-, PR- and HER2negative breast cancer patients? Am J Pathol 175: 1389-1397

Engen JR, Wales TE, Hochrein JM, Meyn III MA, Banu OS, Bahar I, Smithgall TE (2008) Structure and dynamic regulation of Src-family kinases. Cell Mol Life Sci 65: 3058-3073

Frame MC (2002) Src in cancer: deregulation and consequences for cell behaviour. Biochim Biophys Acta 1602: 114-130

Fu Y, Zagozdzon R, Avraham R, Avraham HK (2006) CHK negatively regulates Lyn kinase and suppresses pancreatic cancer cell invasion. Int $J$ Oncol 29: $1453-1458$

Gee JM, Shaw VE, Hiscox SE, McClelland RA, Rushmere NK, Nicholson RI (2006) Deciphering antihormone-induced compensatory mechanisms in breast cancer and their therapeutic implications. Endocr Relat Cancer 13(Suppl 1): S77-S88

Goldenberg-Furmanov M, Stein I, Pikarsky E, Rubin H, Kasem S, Wygoda M, Weinstein I, Reuveni H, Ben Sasson SA (2004) Lyn is a target gene for prostate cancer: sequence-based inhibition induces regression of human tumor xenografts. Cancer Res 64: 1058-1066

Hibbs ML, Dunn AR (1997) Lyn, a src-like tyrosine kinase. Int J Biochem Cell Biol 29: 397-400

Hiscox S, Morgan L, Green TP, Barrow D, Gee J, Nicholson RI (2006) Elevated Src activity promotes cellular invasion and motility in tamoxifen resistant breast cancer cells. Breast Cancer Res Treat 97: $263-274$

Huang F, Reeves K, Han X, Fairchild C, Platero S, Wong TW, Lee F, Shaw P, Clark E (2007) Identification of candidate molecular markers predicting sensitivity in solid tumors to dasatinib: rationale for patient selection. Cancer Res 67: 2226-2238
Hynes NE (2000) Tyrosine kinase signalling in breast cancer. Breast Cancer Res 2: $154-157$

Irby RB, Yeatman TJ (2000) Role of Src expression and activation in human cancer. Oncogene 19: 5636-5642

Kirkegaard T, Edwards J, Tovey S, McGlynn LM, Krishna SN, Mukherjee R, Tam L, Munro AF, Dunne B, Bartlett JM (2006) Observer variation in immunohistochemical analysis of protein expression, time for a change? Histopathology 48: 787-794

Kleber S, Sancho-Martinez I, Wiestler B, Beisel A, Gieffers C, Hill O, Thiemann M, Mueller W, Sykora J, Kuhn A, Schreglmann N, Letellier E, Zuliani C, Klussmann S, Teodorczyk M, Grone HJ, Ganten TM, Sultmann H, Tuttenberg J, von Deimling A, Regnier-Vigouroux A, Herold-Mende C, Martin-Villalba A (2008) Yes and PI3K bind CD95 to signal invasion of glioblastoma. Cancer Cell 13: 235-248

Lee F, Fandi A, Voi M (2008) Overcoming kinase resistance in chronic myeloid leukemia. Int J Biochem Cell Biol 40: 334-343

Likhite VS, Stossi F, Kim K, Katzenellenbogen BS, Katzenellenbogen JA (2006) Kinase-specific phosphorylation of the estrogen receptor changes receptor interactions with ligand, deoxyribonucleic acid, and coregulators associated with alterations in estrogen and tamoxifen activity. Mol Endocrinol 20: $3120-3132$

Manning G, Whyte DB, Martinez R, Hunter T, Sudarsanam S (2002) The protein kinase complement of the human genome. Science 298: $1912-1934$

Martin GS (2001) The hunting of the Src. Nat Rev Mol Cell Biol 2: $467-475$

Masaki T, Igarashi K, Tokuda M, Yukimasa S, Han F, Jin YJ, Li JQ, Yoneyama H, Uchida N, Fujita J, Yoshiji H, Watanabe S, Kurokohchi K, Kuriyama S (2003) pp60c-src activation in lung adenocarcinoma. Eur J Cancer 39: $1447-1455$

Palacios EH, Weiss A (2004) Function of the Src-family kinases, Lck and Fyn, in T-cell development and activation. Oncogene 23: 7990-8000

Park SI, Zhang J, Phillips KA, Araujo JC, Najjar AM, Volgin AY, Gelovani JG, Kim SJ, Wang Z, Gallick GE (2008) Targeting SRC family kinases inhibits growth and lymph node metastases of prostate cancer in an orthotopic nude mouse model. Cancer Res 68: 3323-3333

Reed JC (1999) Dysregulation of apoptosis in cancer. J Clin Oncol 17: $2941-2953$

Rody A, Holtrich U, Pusztai L, Liedtke C, Gaetje R, Ruckhaeberle E, Solbach C, Hanker L, Ahr A, Metzler D, Engels K, Karn T, Kaufmann M (2009) T-cell metagene predicts a favorable prognosis in estrogen receptor-negative and HER2-positive breast cancers. Breast Cancer Res 11: R15

Roginskaya V, Zuo S, Caudell E, Nambudiri G, Kraker AJ, Corey SJ (1999) Therapeutic targeting of Src-kinase Lyn in myeloid leukemic cell growth. Leukemia 13: 855-861

Rudner J, Mueller AC, Matzner N, Huber SM, Handrick R, Belka C, Jendrossek V (2009) The additional loss of Bak and not the lack of the protein tyrosine kinase p56/Lck in one JCaM1.6 subclone caused pronounced apoptosis resistance in response to stimuli of the intrinsic pathway. Apoptosis 14: 711-720

Samraj AK, Stroh C, Fischer U, Schulze-Osthoff K (2006) The tyrosine kinase Lck is a positive regulator of the mitochondrial apoptosis pathway by controlling Bak expression. Oncogene 25: 186-197

Stehelin D, Guntaka RV, Varmus HE, Bishop JM (1976) Purification of DNA complementary to nucleotide sequences required for neoplastic transformation of fibroblasts by avian sarcoma viruses. J Mol Biol 101: $349-365$ 
Tatarov O, Mitchell TJ, Seywright M, Leung HY, Brunton VG, Edwards J (2009) SRC family kinase activity is up-regulated in hormone-refractory prostate cancer. Clin Cancer Res 15: 3540-3549

Tovey S, Dunne B, Witton CJ, Forsyth A, Cooke TG, Bartlett JM (2005) Can molecular markers predict when to implement treatment with aromatase inhibitors in invasive breast cancer? Clin Cancer Res 11: 4835-4842

Verbeek BS, Vroom TM, Adriaansen-Slot SS, Ottenhoff-Kalff AE, Geertzema JG, Hennipman A, Rijksen G (1996) c-Src protein expression is increased in human breast cancer. An immunohistochemical and biochemical analysis. J Pathol 180: 383-388
Warmuth M, Simon N, Mitina O, Mathes R, Fabbro D, Manley PW, Buchdunger E, Forster K, Moarefi I, Hallek M (2003) Dual-specific Src and Abl kinase inhibitors, PP1 and CGP76030, inhibit growth and survival of cells expressing imatinib mesylate-resistant Bcr-Abl kinases. Blood 101: $664-672$

Wilson MB, Schreiner SJ, Choi HJ, Kamens J, Smithgall TE (2002) Selective pyrrolo-pyrimidine inhibitors reveal a necessary role for Src family kinases in Bcr-Abl signal transduction and oncogenesis. Oncogene 21: $8075-8088$

Yeatman TJ (2004) A renaissance for SRC. Nat Rev Cancer 4: 470-480 